\title{
Comparison of intensity and post-effort response in three interval trainings in young tennis players: running interval, specific interval, and specific intermittent training
}

\author{
David Suárez-Rodríguez', Miguel del Valle²
}

'Universidad Isabel I. Burgos. ${ }^{2}$ Universidad de Oviedo.

doi: 10.18176/archmeddeporte.00025

Recibido: $15 / 05 / 2020$

Aceptado: 01/12/2020

Key words:

Tennis. Specific training

High intensity.

Intermittent. Recovery.

\section{Summary}

Introduction: In recent years, considerable interest has been shown in adapting training to the specific characteristics of tennis. The use of intermittent exercise seems to adapt better to the sport's work/recovery structure and using specific movements allows for local adaptations and complex work. Nevertheless, we need to achieve a level of intensity that is at least similar to what is achieved when continuous running is used. The ability to recover between points is also a decisive factor in terms of performance. Our hypothesis is that recovery depends on stimulus type, which means the most suitable stimuli must be chosen to improve this capacity.

Material and method: Our study's goal was to compare the intensity and post-effort behaviour triggered by three types of exercise: continuous running with 2-minute intervals (GIT), rallies with 2-minute intervals (SIT) and intermittent rallies (SIIT). We measured heart rate (HR) and blood lactate levels during the three exercises, as well as the recovery to 130 beats and in the first 10 and 20 seconds post-effort.

Results: Heart rate intensity was significantly higher in SIT than in GIT and lactate levels were higher in both SIT and SIIT compared to GIT. Heart rate recovery is significantly slower in both specific exercises, increasing in the first 10 and 20 seconds with SIIT. Discussion: We have reached the conclusion that specific training led to greater intensity in the specific exercises. Post-effort response is slower in the specific trainings and paradoxical in the initial seconds of intermittent training
Palabras clave: Tenis. Específico. Intensidad.

Recuperación. Interválico. Intermitente.

\section{Comparación de la intensidad y la respuesta post-esfuerzo en tres entrenamientos interválicos en jóvenes tenistas: interválico de carrera, interválico específico e intermitente específico}

\section{Resumen}

Introducción: En los últimos años se ha producido un gran interés por adaptar el entrenamiento a la especificidad del tenis. El uso de ejercicios intermitentes parece adaptarse más a la estructura de trabajo/recuperación de este deporte que las actividades continuas. A su vez, utilizar movimientos específicos permite adaptaciones locales y trabajar de forma compleja. Sin embargo, se necesita alcanzar un nivel de intensidad que sea al menos similar al que se logra cuando se utiliza la carrera continua. La capacidad de recuperar entre puntos es un factor decisivo en el rendimiento. Nuestra hipótesis es que la recuperación puede ser diferente según sea el tipo de estímulo y que habrá que escoger los más adecuados para mejorar esta capacidad. No obstante, es necesario que estos entrenamientos tengan una intensidad al menos similar a cuando se utiliza la carrera continua. Material y método: Nuestro objetivo en este estudio es comparar la intensidad y el comportamiento post-esfuerzo de tres ejercicios: carrera continua con intervalos de 2 minutos (GIT), golpeo de bolas con intervalos de 2 minutos (SIT), golpeo de bolas con intermitencias (SIIT). Hemos medido la HR y el lactato durante los tres ejercicios y la recuperación a 130 pulsaciones, y en los 10 y 20 segundos post-esfuerzo.

Resultados: La intensidad cardiaca fue significativamente mayor en SIT que en GIT, y el lactato superior en SIT y SIIT, respecto a GIT. La recuperación cardiaca es significativamente más lenta en ambos ejercicios específicos, llegando a incrementarse en los 10 y 20 segundos iníciales en SIIT.

Discusión: Concluimos que con el entrenamiento específico se ha alcanzado una elevada intensidad en los trabajos específicos. La respuesta post-esfuerzo es más lenta en los entrenamientos específicos, y paradójica en los primeros segundos en el entrenamiento intermitente. 


\section{Introduction}

The ability to change direction at speed is essential to performance in sports such as tennis ${ }^{1}$. The ability to undertake a number of actions at a high rate of intensity depends on different factors such as explosive strength ${ }^{2}$ and an optimum aerobic leve $\left.\right|^{3,4}$. It is therefore interesting to understand the characteristics of different methods of high intensity training in order to ensure improved performance, taking into consideration the duration and intensity of the training and whether motor action is specific or general.

In recent years, studies of specific types of exercises in team sports ${ }^{5-7}$ and in tennis ${ }^{8}$ have been undertaken, in which high levels of intensity have been identified.

Recovery between specific actions shows highly variable behaviour among sportspeople. Even in sportspeople with a similar level of cardiorespiratory resistance, recovery between intermittent actions appears in very different ways ${ }^{9}$.

Monitoring heart rate reduction is a suitable way of measuring an athlete's fitness, while it will also show us if there is positive adaptation to the type of effort, which means training must consider the kind of load created by the characteristics of each different sport ${ }^{9}$.

Blood lactate measuring will provide us with data regarding glycoIytic participation and the different disposal dynamic, according to the characteristics of the effort.

Therefore, it is of great interest to study the different specific tennisbased exercises and their intensity, but also the analysis of the recovery stages could be specially relevant to deepen in a in a training method that is better suited to the needs of this sport.

\section{Material and method}

\section{Participants}

The sample consisted of 13 healthy male tennis players. The average age was $17 \pm 2$ years, the average height $176.5 \pm 4.4 \mathrm{~cm}$ and the average mass $69.5 \pm 3.4 \mathrm{~kg}$. Weekly training hours and years of play were $12 \pm 2 \mathrm{~h} /$ week and $7 \pm 3$ years, respectively. All subjects provided their consent at the beginning of the research.

Players frequently play in national level tournaments and each one undergoes an extended pre-season training period of 3 months They are used to general running-based continuous and interval training.

\section{Design and Procedures}

Before carrying out the study, a Conconi test was undertaken using an ergometrics test in the laboratory to obtain each subject's maximum heart rate. The ergometric values were taken at 18:00 hours on different days and the subjects were told not to undertake any intense effort during the previous 24 hours or eat any food in the 2 hours before the values were registered. The test consisted of a progression run with a constant $5 \%$ gradient at an initial speed of $5 \mathrm{~km} / \mathrm{h}$, increasing by $1 \mathrm{~km} / \mathrm{h}$ every minute.

The experimental study was carried out at the Asturias Regional Sports Centre (Centro Regional de Deportes del Principado de Asturias) during the pre-season period. Running tests were undertaken on a regulation-size grass football field. Specific tennis tests were undertaken on medium-speed synthetic resin tennis courts.

Three test protocols were designed:

- Running interval training: General Interval Training (GIT).

- Interval stroke-based training: Specific Interval Training (SIT).

- Intermittent interval stroke-based training: Specific Intermittent Interval Training (SIIT).

The exercises were carried out over the space of two weeks: first, the running work; then, the stroke-based exercises; and finally, the intermittent stroke-based exercises. Each athlete undertook three tests per week with 72 hours' rest between each test.

\section{Test protocols}

- GIT. Running at a 90\% subjective intensity rate, made up of 3 sets of 3 repetitions, with 130-beat recovery between repetitions and at 120 beats between sets for being a heart rate commonly used in interval training.

Before the exercise, the players warmed up with a gentle, continuous 10-minute run.

- SIT. This exercise used the same structure ( $3 \times 3 \times 2$ minutes) and recovery patterns and were based on forehand and backhand strokes, on both sides of the court (from sideline to sideline) as cross-shots, behind the service box. Movement and shot rate was a 90\% subjective intensity, set by the player. To do this, the trainer threw the ball with their hand into the area surrounding the sidelines.

- SIIT. This exercise used the same structure of work and recovery between repetitions and sets. Nevertheless, micro-intervals of work and recovery were undertaken in each repetition in the foIlowing way: 20-second rally, 20-second recovery, 20-second rally and subsequently 15-second intermittences until the 2-minute period was completed. Interval times were varied to facilitate the initial elevation of HR and to adjust more to the variability of tennis. Once again, the trainer threw the ball at the rate set by the player, hitting with the forehand and backhand and returning to the centre of the court. The recovery intermittence phases were always passive.

As a warm-up for both specific exercises, players undertook a gentle 10-minute rally.

The same monitoring approach was used for the three tests. Polar heart rate monitors were used (Polar RS400 Finland), registering heart rate data at all times. Blood lactate levels were measured with portable analysers Lactate Pro 2 (Arkray, Japan). Blood samples were taken in the ear, at the end of the three sets and 3 minutes after completing the test, taking a sample volume of approximately $0,3 \mathrm{Ml}$, in order to evaluate lactate levels and recovery.

All the data were subsequently organised, analysed and evaluated.

\section{Statistical Analysis}

The two-tailed t-test was used for comparing sample averages, analysing the null hypothesis that the averages are the same compared with the alternative that they are not. With a p-value of 0.05 or lower, a significance level of $95 \%$ is achieved. 


\section{Results}

\section{Heart Rate}

A more intense heart rate was achieved in the two specific trainings, with a significant difference in SIT compared to GIT (0.0484) (Table 1). No statistically significant differences were found between the specific exercises $(\geq 0.05)$, with similar behaviour between the total values and when comparing the different sets.

\section{Lactate}

On completing the exercise, it can be seen that lactate levels are significantly higher in SIT and SIIT than in GIT (Table 2). There is also a significant difference in the first set of exercises, with SIT-SIIT > GIT, indicating greater intensity from the very first repetitions of the specific training exercises. There are no differences between the specific playbased exercises.

\section{Recovery heart rate}

Recovery in the running-based efforts was faster than in the playbased exercises in all three sets, with 130 beats achieved sooner than in the specific tennis-based efforts (GIT > SIT-SIIT).

As for recoveries in the initial seconds, significant differences can be seen, with swifter reduction in the running-based exercises compared to the play-based ones. HR reduction is also greater between the specific non-intermittent exercises compared to those involving intermittent work and recovery (GIT > SIT, and GIT-SIT > SIIT) (Table 3).

Table 1. Average rates of maximum individual $\mathrm{HR}$ as a reference parameter. Average HR and percentage from maximum HR as a benchmark.

\begin{tabular}{lccc}
\hline & GIT & SIT & SIIT \\
\hline Maximum individual HR (bits) & 198.69 & 198.69 & 198.69 \\
Average HR (bits / \%) & $172.02 /$ & $180.59 /$ & $177.87 /$ \\
& 86.57 & 90.89 & 89.52 \\
\hline
\end{tabular}

HR. SIT > GIT 0.0484.

GIT: General Interval Training; SIT:Specific Interval Training; SIIT:Specific Intermittent Interval Training.

Table 2. Lactate averages in $\mathrm{mMol} / \mathrm{l}$ in sets 1,2 and 3 in the three types of training.

\begin{tabular}{llll}
\hline & GIT & SIT & SIIT \\
\hline Set 1 & 4.86 & 7.04 & 6.97 \\
Set 2 & 6.68 & 6.74 & 7.46 \\
Set 3 & 6.63 & 8.02 & 8.07 \\
\hline
\end{tabular}

Lact: SIT Set $3>$ GIT Set 30.0215 / SIIT Set $3>$ GIT Set 30.0503 .

SIT Set $1>$ GIT Set $10.0011 /$ SIIT Set $1>$ GIT Set 10.0101 .

GIT: General Interval Training; SIT: Specific Interval Training; SIIT: Specific Intermittent Interval Training.
Table 3. Average time invested in recovery to 130 beats (Recovery 130). Reduce beats in the first 10 and 20 seconds post-effort (Recovery 10 seconds, Recovery 20 seconds).

\begin{tabular}{lccc}
\hline & GIT & SIT & SIIT \\
\hline Recovery 130 bits (seconds) & 56.36 & 86.55 & 76.54 \\
Recovery 10 seconds (seconds) & -5.25 & -1.95 & 1.22 \\
Recovery 20 seconds (seconds) & -13.96 & -7.34 & -3.06 \\
\hline
\end{tabular}

Recovery 130 beats. GIT > SIT 0.0000 / GIT > SIIT 0.0027

Recovery 10 seconds. GIT > SIT 0.0003 / GIT > SIIT 0.0000 / SIT > SIIT 0.0035

Recovery 20 seconds. GIT > SIT 0.0010 / GIT > SIIT 0.0000 / SIT > SIIT 0.0102

GIT: General Interval Training; SIT: Specific Interval Training; SIIT: Specific Intermittent Interval Training.

Table 4. Lactate average in $\mathrm{mmol} / \mathrm{l} 3$ minutes post-effort and the reduction rate between end values and 3-minute post-effort levels.

\begin{tabular}{llll}
\hline & GIT & SIT & SIIT \\
\hline Lactate averages after 3 minutes (mMol) & 4.26 & 5.87 & 6.70 \\
Reduction rate (mMol) & 2.37 & 2.15 & 1.37 \\
\hline
\end{tabular}

Recovery lactate. GIT > SIIT 0.0010

GIT: General Interval Training; SIT: Specific Interval Training; SIIT: Specific Intermittent Interval Training.

\section{Recovery lactate}

After three minutes of recovery, significantly lower values were provided with GIT than with SIIT (Table 4). Nevertheless, when the reduction rates or the fall in blood lactate levels are viewed by comparing the end values to those found 3 minutes after, they are not significant, although they are greater in the running-based training (Table 4 and annexed Table 2).

\section{Discussion}

\section{HR Intensity}

In our study, the specific tennis-based exercises showed higher HRs compared to the general continuous running exercises (Figure 1), which may be down to the type of movements undertaken (lateral movement, acceleration and deceleration, which all involve constant explosive actions and eccentric tensions). SIT showed a significantly greater HR intensity than GIT. Dellal et al. ${ }^{10}$ observed in a study with 10 professional footballers using high-intensity intermittent exercises (30:30, 20:20 and 15:15) that specific actions are more glycolytic and show that accelerations and decelerations lead to the higher participation of glycolytic pathways, with higher HR and lactate values.

\section{Lactate intensity}

Lactate behaviour is very similar in SIT and SIIT. Nevertheless, significantly higher values are shown between the two types of specific training and the general training exercise (Figure 2). The non-significant difference in heart rate between SIIT and GIT accompanied by significant lactate levels may indicate increased participation of fast twitch muscle 
Figure 1. Distribution of individuals' average HR for GIT, SIT and SIIT.

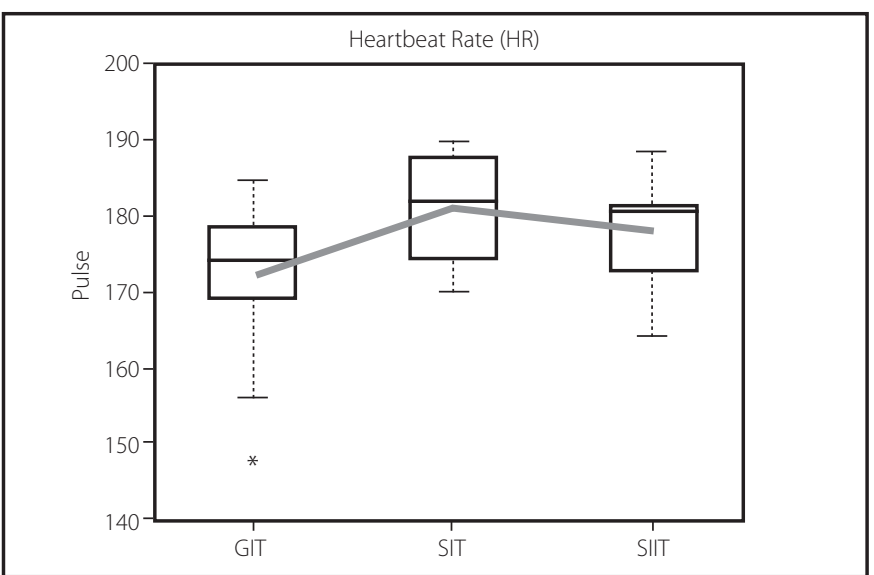

GIT: General Interval Training; SIT:Specific Interval Training; SIIT: Specific Intermittent Interval Training. The box shows the dispersion of the sample, defined by the $25^{\text {th }}$ (lower limit) and $75^{\text {th }}$ (upper limit) percentiles; the red line defines the median and the black lines the upper and lower limits, outside of which values are considered to be outliers. These are marked with red crosses.

Figure 2. Distribution of individuals' lactate levels in GIT, SIT and SIIT.

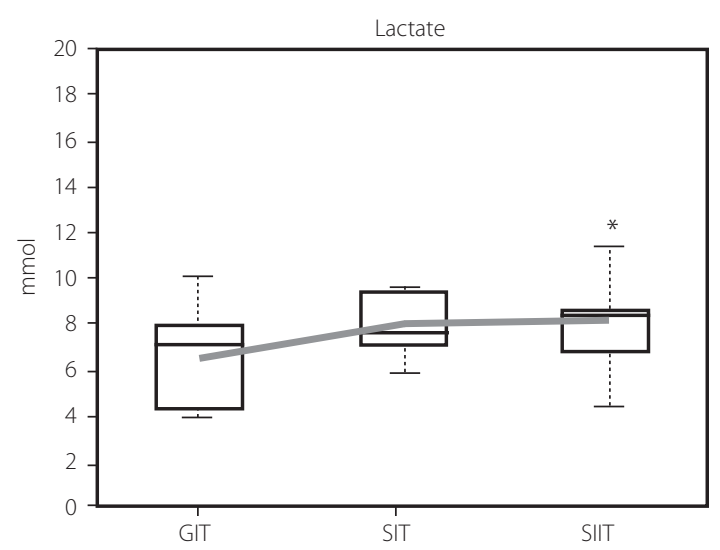

GIT: General Interval Training; SIT: Specific Interval Training; SIIT: Specific Intermittent Interval Training. The box shows the dispersion of the sample, defined by the $25^{\text {th }}$ (lower limit) and $75^{\text {th }}$ (upper limit) percentiles; the red line defines the median and the black lines the upper and lower limits, outside of which values are considered to be outliers. These are marked with red crosses.

fibres in intermittent training. Protocols involving intermittent work with very short periods of work and recovery may increase the engagement of fast twitch muscle fibres ${ }^{11}$. As in our study, Zouhal et al. ${ }^{12}$ found higher $\mathrm{HR}$ and lactate values in specific football-related efforts compared with high intensity short interval running exercises (15:15).

\section{Heart rate recovery}

In intermittent sports such as tennis, optimum recovery between points is decisive. Greater engagement of fast twitch muscle fibres and anaerobic participation leads to sympathetic activation ${ }^{13,14}$.
We have observed different behaviour in the specific exercises, with slower post-effort recovery (Figure 3). The delay in recovery in SIT compared to GIT may be explained by increased intensity. Nevertheless, intensity in SIIT was not significantly greater, which means that the explanation may lie in the dynamic of the actions, with the increased participation of fast twitch fibres and higher blood lactate concentrations.

When work is intermittent and high intensity, a delay in heart rate activation may be caused in response to the motor action, along with a stage of maximum HR in the initial seconds of recovery ${ }^{15}$.

In our study, the response 10 and 20 seconds post-effort was significantly slower in SIIT than in SIT (Figures 4 and 5), showing a post-effort increase in HR. For Hamar et al. ${ }^{16}$, when work is short and intense, heart rate does not show sudden changes but is slightly higher during the initial seconds of rest.

Figure 3. Distribution of 130-beat recovery for GIT, SIT and SIIT.

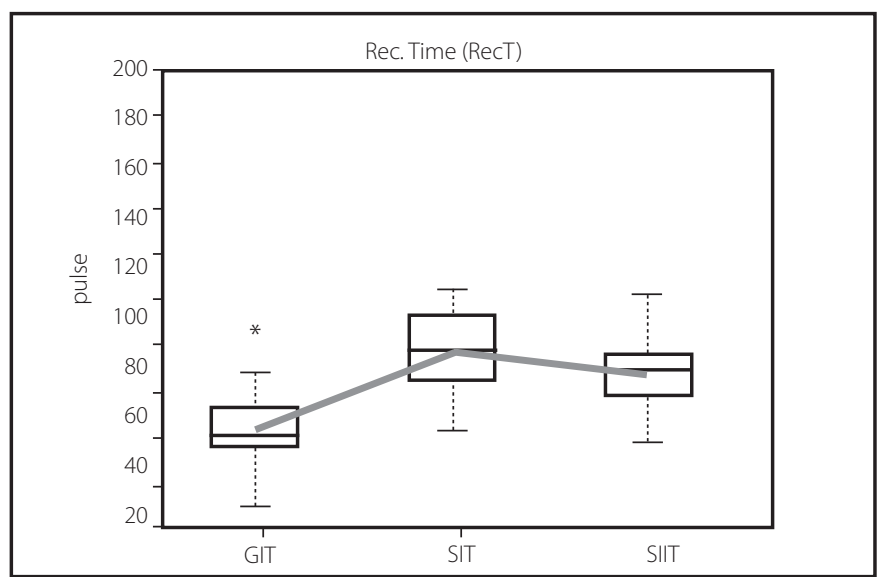

GIT: General Interval Training; SIT: Specific Interval Training; SIIT: Specific Intermittent Interval Training. The box shows the dispersion of the sample, defined by the $25^{\text {th }}$ (lower limit) and $75^{\text {th }}$ (upper limit) percentiles; the red line defines the median and the black lines the upper and lower limits, outside of which values are considered to be outliers. These are marked with red crosses.

Figure 4. Distribution of recovery 10 (R10) seconds later for GIT, SIT and SIIT.

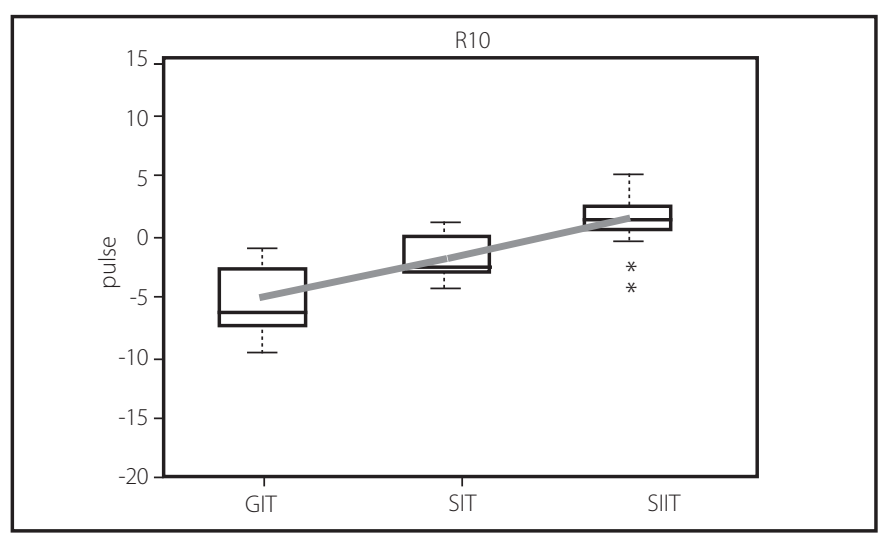

GIT: General Interval Training: SIT:Specific Interval Training: SIIT:Specific Intermittent Interval Training. The box shows the dispersion of the sample, defined by the $25^{\text {th }}$ (lower limit) and $75^{\text {th }}$ (upper limit) percentiles; the red line defines the median and the black lines the upper and lower limits, outside of which values are considered to be outliers. These are marked with red crosses. 
Figure 5. Distribution of recovery 20 (R20) seconds later for GIT, SIT and SIIT.

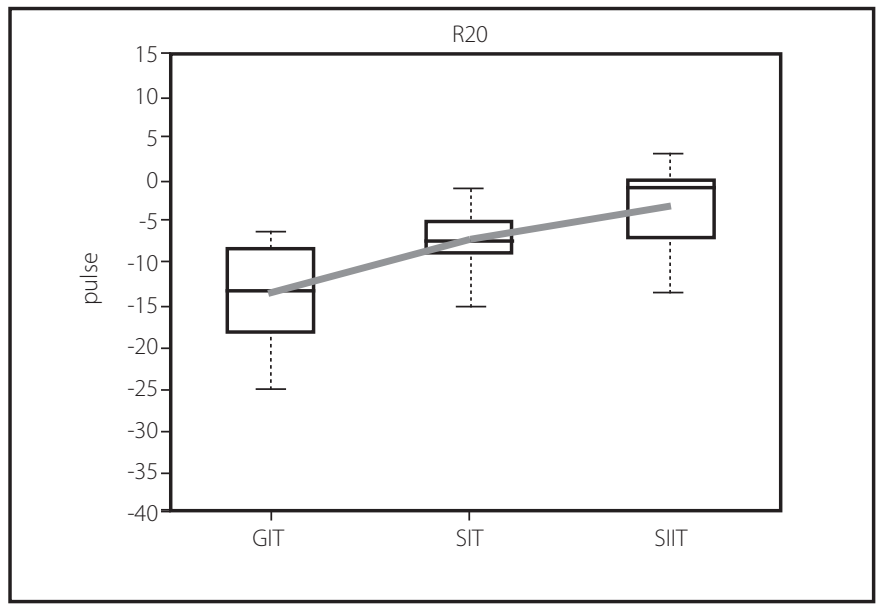

GIT:General Interval Training; SIT: Specific Interval Training; SIIT: Specific Intermittent Interval Training. The box shows the dispersion of the sample, defined by the $25^{\text {th }}$ (lower limit) and $75^{\text {th }}$ (upper limit) percentiles; the red line defines the median and the black lines the upper and lower limits, outside of which values are considered to be outliers. These are marked with red crosses.

Figure 6. Distribution of lactate recovery. Difference between final lactate and lactate after 3 minutes (Reduction Rate) for GIT, SIT and SIIT.

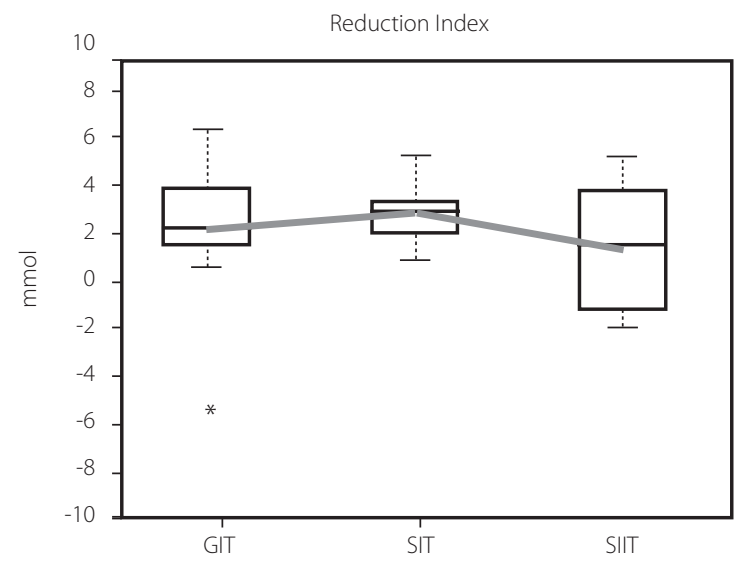

GIT: General Interval Training; SIT: Specific Interval Training; SIIT: Specific Intermittent Interval Training. The box shows the dispersion of the sample, defined by the $25^{\text {th }}$ (lower limit) and $75^{\text {th }}$ (upper limit) percentiles; the red line defines the median and the black lines the upper and lower limits, outside of which values are considered to be outliers. These are marked with red crosses.

Different behaviour can be seen at the 130-beat recovery stage compared to the initial post-effort stages. The immediate response after concluding the exercise is clearly different in SIIT, with an increase during the initial 10 and 20 seconds, constituting paradoxical behaviour. The mechanisms used in post-effort recovery are different in the initial seconds with the deactivation of the sympathetic system, compared with the period after recovery, which depends on the activation of the parasympathetic system ${ }^{17}$.
The choice of one type of work or another will be decisive in improving recovery between points (a maximum of 20-25 seconds in a match), which, in many cases, is decisive in tennis.

\section{Lactate recovery}

As far as lactate recovery is concerned, the differences are not so clear. While measurements after 3 minutes are significantly lower in SIIT compared with GIT, when the reduction between post-effort measurement and measurement after 3 minutes is taken into account (reduction rate), the difference is not significant. Nevertheless, lower values can be seen in the reduction rate in both specific types of exercise and especially in SIIT (Figure 6). This less significant drop in lactate concentration levels may be down to the increased participation of the glycolytic fibres ${ }^{11}$ and a more local activation with a more gradual presence of lactate in the lactacidaemia measurements.

The different behaviour both in terms of heart rate and lactate level recovery in intermittent tennis-based exercises, could be explained by a greater muscle mass involved and a more intense eccentric work. The study shows that this type of training can act specifically on the short rest periods that occur during a tennis match.

\section{Conclusion}

In our study, players have registered higher HR and blood lactate values in specific efforts, related to increased intensity of work. Specific tennis-based efforts show slower recovery compared to general running exercises. Specific intermittent training has shown paradoxical behaviour in the initial seconds of recovery, with a raised HR in the first 10 and 20 seconds. Consequently, specific training allows for work to be undertaken at sufficiently high levels of intensity so as to allow for maximum training of aerobic potential. Specific intermittent training allows for high intensity complex training, with action affecting the immediate recovery mechanisms that are so decisive for tennis players' performance.

\section{Conflict of interest}

The authors do not declare a conflict of interest.

\section{Bibliography}

1. Brughelli M, Cronin J, Levin G \& Chaouachi A. Understanding Change of Direction Ability in Sport: A Review of Resistance Training Studies. Sports Med. 2008;38:1045-63.

2. Stojanovic MD, Ostojic SM, Calleja-González J, Milosevic Z \& Mikic M. Correlation between explosive strength aerobic power and repeated sprint ability in elite basketball players. J Sports Med \& Phys Fit. 2012;52:375-81.

3. Bishop D, Edge J \& Goodman C. Muscle buffer capacity and aerobic fitness are associated with repeated-sprint ability in women. Eur J Appl Physiol. 2004;92:540-7.

4. Bishop D \& Spencer M. Determinants of repeated sprint ability in well-trained teamsport and endurance-trained athletes. J Sports Med Phys Fitness. 2004; 44:1-6.

5. Hoff J, Wisloff U, Engen LC, Kemi OJ \& Helgerud J. Soccer specific aerobic endurance training. Br J Sports Med. 2002;36:218-21

6. Kemi OJ, Hoff J, Engen LC, Helgerud J \& Wisloff U. Soccer specific testing of maximal oxygen uptake. J Sports Med Phys Fit. 2003;43:139-44.

7. Chamari K, Hachana Y, Kaouech F, Jeddi R, Moussa-Chamari I \& Wisløff U. Edurance training and testing with the ball in young elite soccer players. Br J Sports Med. 2005; 39:24-8. 
8. Fernández-Fernández J, Sanz-Rivas D, Sánchez-Muñoz C, de la Aleja Tellez JG, Buchheit M \& Mendez-Villanueva A. Physiological Responses to On-Court vs Running Interval Training in Competitive Tennis Players. J Sports Sci Med. 2011;10:540-5.

9. Haydar B, Al Haddad H, Ahmaidi S \& Buchheit M. Assessing inter-effort Recovery and change of direction ability with 30-15 intermittent fitness test. J Sports Sci Med. 2011; 10:346-54.

10. Dellal A, Keller D, Carling Ch, Chaouachi A, Wong DelP \& Chamari K. Physiologic effects of directional changes in intermittent exercise in soccer players. J Strength Con Res. 2010;24:3219-26.

11. Belfry GR, Raymer GH, Marsh GD, Paterson DH, Thompson RT, Thomas SG. Muscle metabolic status and acid-base balance during 10-s work:5-s recovery intermittent and continuous exercise. J Appl Physiol. 2012.113:410-7.

12. Zouhal H, LeMoal E, Wong DP, BenOunis O, Castagna C, Duluc C, Owen AL \& Drust B. Physiological Responses of General vs. Specific Aerobic Endurance Exercises in Soccer. As J Sports Med. 2013:4:212-20.
13. Buchheit M, Laursen PB \& Ahmaidi S. Parasympathetic reactivation after repeated sprint exercise. Am J Physiol Heart Circ Physiol. 2007;293:133-41.

14. Buchheit M, Al Haddad H, Millet GP, Lepretre PM, Newton M \& Ahmaidi S. Cardiorespiratory and cardiac autonomic responses to 30-15 intermittent fitnestes in team sports players. J Strength Cond Res. 2009;3:93-100.

15. Kang J, Mangine GT, Ratamess NA, Faigenbaum AD \& Hoffman JR. Influence of intensity fluctuation on exercise metabolism. Eur J Appl Physiol. 2007;100:253-60.

16. Hamar D, Komadel L, Tkac M \& Kuthanova O. Cinética de los parámetros ventilatorios y de intercambio de gases durante el ejercicio intermitente. Arch Med Deport. 1989, $6: 11-5$.

17. Coote JH. Recovery of heart rate following intense dynamic exercise. ExpPhysiol. 2009; 95:431-40. 